\title{
Social Media \& Business Growth: Why Small/Medium-Scale Enterprises in the Developing World Should Take an Advantage Of it (A Case of the country Ghana)
}

\author{
Suzzie Adobea Apenteng ${ }^{1}$, Nina Pearl Doe ${ }^{2}$ \\ ${ }^{\text {I}}$ (Department of Computer Engineering , All Nations University College, Ghana) \\ ${ }^{2}$ (Department of Computer Science and Engineering, Anna University, India)
}

\begin{abstract}
Small and medium-sized businesses (SMBs) are considered engines for economic growth, and with good reason. They are usually eager to grow their companies, and are always looking for new ways to raise the profile of their brands and rev up their marketing efforts. Social media plays a critical role in these growth and marketing efforts. In Ghana more people are joining social media but businesses are failing to take opportunity to market their products there since they is not enough statistical proof of any return of investment and there is no proper understanding of how to use social media as a means of marketing their products. Today, more than a billion numbers of people can be seen on one or more social media sites in an hour. This paper is focused on highlighting the need for small to medium-scale businesses in Ghana to take advantage of the social media buzz to grow their businesses.
\end{abstract}

Keywords: Social Media, Small and medium-sized businesses (SMBs), business growth, Facebook, Ghana

\subsection{What is Social Media?}

\section{Introduction}

The word Media comes from the Latin plural of "medium" which is said to be a means by which something is communicated or expressed.

Social media refers to the means of interactions among people in which they create, share, and/or exchange information and ideas in virtual communities and networks [1]. Some of the popular social media sites are Facebook, Twitter, YouTube and LinkedIn.

A recent survey from LinkedIn found $80 \%$ of small business owners turning to social media platforms to generate revenue and find new customers. The survey, conducted in November 2013 by LinkedIn and research firm TNS, finds that "hyper growth" businesses - those experiencing significant revenue growth over the last year - are spending more than their slower-growing peers on social media. Seventy-three percent of high-performing small businesses say they increased spending on social media and social ads in the last year. In comparison, only $42 \%$ of small businesses experiencing no growth did the same. The fast-growing small businesses report social media to be an effective marketing tool. Nine out of ten say their social media efforts help maintain a company presence and identity, while $82 \%$ say the platforms help generate new leads [13].

\section{$1.2 \quad$ Types of Social Media}

According to the Outthink Group [10], there are six (6) types of Social Media, which are as follows:

1. Social Networks: These are services that allow one to connect with other people who share similar interests and background. Facebook and LinkedIn are the most popular in this category.

2. Media Sharing: Services is this category is the type that allows the user to upload and share various forms of media such as videos. YouTube can be said to be one of the most popular form of media sharing in this group.

3. Bookmarking Sites: Bookmarking sites are sites that allow you to save, organize and manage links to various websites around the Internet. The most popular are StumbleUpon and Delicious.

4. Micro blogging: These services focus on short updates that are pushed out to anyone subscribed to receive updates. Example is Twitter.

5. Blog Comments and Forums: We can say that online forums have allowed its members to hold conversations by posting messages. Blog comments are attached to blogs and usually the discussion centres around the topic of the blog post.

6. Social News: These are services that permit people to post various news items to outside articles and then allow its users to vote on the items. The voting is the core feature of this service as the community decides which news items get seen by more people. An example of such service is Reddit. 


\subsection{Uses of Social Media}

Social Media can be used for various purposes. It could be used to make friends, sell products and services, educate people, and listen to music and watch videos. However, there are innovative ways of using social media as described by David A. Smith [9]. These innovative ways are listed and explained below:

a. Business to Consumer (B2C): Here businesses use social media as a platform to reach out to their consumers. This when done right increases the Return of Investment (ROI) of the company. As quoted by Smith, Domino's Pizza in the UK reported a $29 \%$ increase in pre=tax profits to $£ 17.5 \mathrm{~m}$ in July 2010 , largely owing to an increase in e-commerce.

b. Business to Business (B2B): This is an innovative way for businesses to employ internally for external marketing or research and development $(\mathrm{R} \& \mathrm{D})$.

c. Government to Citizens (G2C): Governments can adapt this use of social media to ask its members of the public on their opinion on several government policies and many more. By doing this, social networks will bring likeminded citizens to act and collectively share their ideas which in the long run will help shape the nation and increase impact. Example can be said of the UK when her Coalition Government brought about 'The Spending Challenge' in mid 2010. The Spending Challenge acted as forum for suggestions on what services and programs of the government could be cut and how it should be done.

d. Peer to Peer (P2P): Many social networks and communities are also innovating at the peer-to-peer level. Social gaming is an example of P2P and it is growing rapidly. Colloquially, games on these social networking sites are called social games. An example is PackRat Games in which the main game play involves socializing like chatting or flirting.

\subsection{Benefits of Social Media for Businesses}

A Small / Medium - Scale Business or a start-up can benefit from social media in diverse ways, which can include the following: an increase in its ROI, Customers and many more [5,6,7].

a. Productivity Benefits: When businesses begin to use social media as a marketing tool by building a strong visible digital/online presence, these businesses tend to gain in terms of productivity because they are able to reach to a wider market on the Internet. This in the long run brings about an increase in the business' ROI.

b. Increase in Customers/Clientele: Businesses are able to increase their number of potential customers when they use social media. For example, when one client or customer hits the like button of your company's page on say Facebook, it is seen on her wall and in all her friends feeds which can intrigue another friend who might probably be not a customer to click on the link to your page to see why his/her friend liked your page and this will not just bring you followers but potential customers as well.

c. Wider Knowledge Pool: According to KPMG [2] International publication on Going Social: How Businesses are making the most out of social media, $88.8 \%$ of experienced managers believed that social media increased their companies knowledge pool.

d. Cost Savings \& Insights: The use of social media can eliminate months of slow and expensive production by getting real-time data and feedback and being able to adjust quickly multiple campaigns to make the highest impact where possible. Also the social media platform will provide the insight you need to know about buyers' dynamics and motivations, which can be used to refine and tailor your content to launch rich campaigns.

\section{a. Methods}

\section{Methods and Findings}

We used the survey design method where a number of questions were drafted and given to the public to respond to this questionnaire. The intention behind the survey was mainly to gather data on the public views concerning businesses and social media. The survey analytics software we used does not permit for any form of manipulation as it begins its analytics process as soon as a survey is submitted. The outcome of the analysis will be represented in the form of bar graphs and tables where applicable.

\section{b. Findings}

There were 100 samples selected, 97 returned their questionnaires, giving a response rate of $97 \%$. The questionnaires were given out to know the most preferred social media site of consumers and their reactions on companies' advertisements.

From the survey, we found that a $100 \%$ of our respondents were on one of the many social media sites with $91.75 \%$ of the respondents on Facebook followed a 50.52\% on YouTube and $40.21 \%$ on LinkedIn and a whopping $67.01 \%$ of the respondents check their social networking sites on daily basis with only $2.06 \%$ who are occasional users as seen in the Fig 1 and Fig 2 below. 


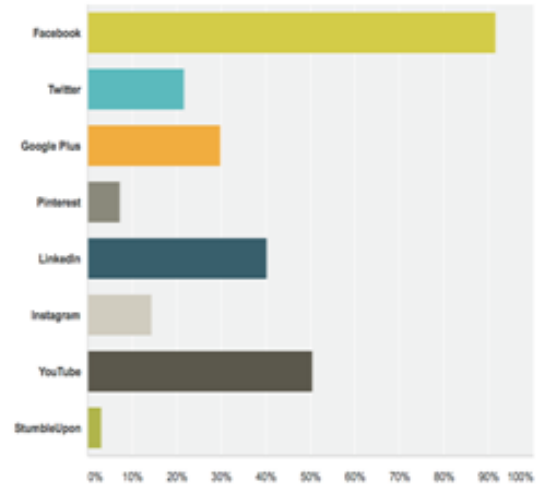

Fig 1. Most popular social media in Ghana

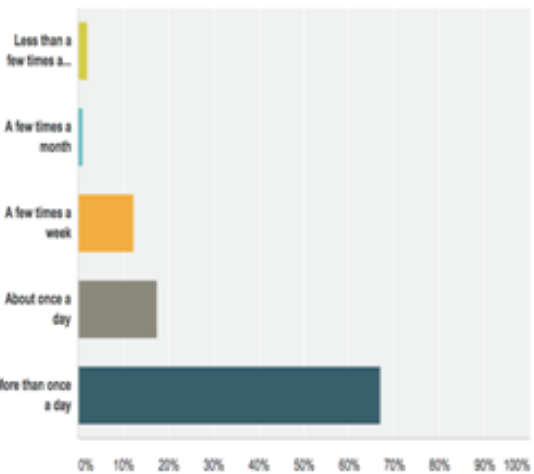

Fig 2. Frequency of social media use

A combined total of 76 respondents, representing $78.35 \%$ of the total respondents (Table 1) felt that Social Media plays an important aspect in their lives which we believe every business should take advantage of this importance. Table 2 shows how important people feel when companies interact with them directly and based on that, they are more willing to purchase the company's product.

Table l: Importance of Social Media to Consumer

\begin{tabular}{|c|c|c|}
\hline Nsection & 1 Resoms & , \\
\hline 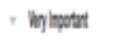 & $e x$ & 4 \\
\hline , Snetalowost & xan & J \\
\hline , hat & 158 & \& \\
\hline , kethowtet & $2 x$ & 2 \\
\hline id & & 9 \\
\hline
\end{tabular}

Table 2: Consumers feeling when companies interacts with them via Social Media

\begin{tabular}{|c|c|c|}
\hline Asser Coocas & + Responss & , \\
\hline Vhy leppesat & 8 ax & 4 \\
\hline V Sentarimpost & $1 \mathrm{tgs}$ & 18 \\
\hline Inpost & vas & z \\
\hline N Methr & 12.15 & $\pi$ \\
\hline V Netimport & 1285 & 13 \\
\hline Tia & & \% \\
\hline
\end{tabular}

In Fig 3, the statistics showed that majority of the subscribers of the various social network sites prefer to buy items that are advertised on Facebook. Fig 4 shows that users are more willing to share their experiences with others, thus, majority will advertise for the company that gives them satisfaction even without the knowledge of the company itself.

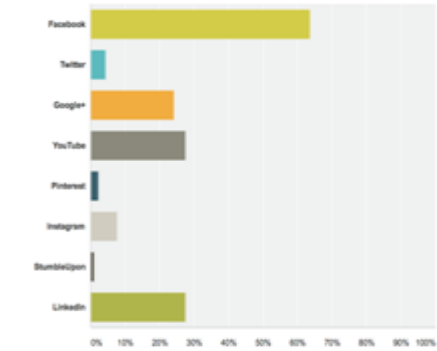

Fig 3: Social Media Preference by Consumers

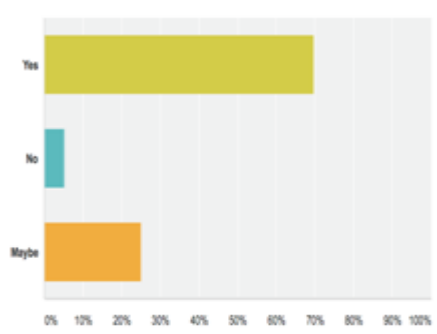

Fig 4: Probability of a satisfied consumer recommending a product or business to a friend

Based on the figures and tables in the survey, it can be observed that if small and medium scale enterprises in Ghana will take the advantage of marketing on social network sites, they will be able to reach a majority of users who will be willing to share experiences with their products with their contacts. These contacts are likely to also share with others, which can go a long way to expose the companies to even other countries. This can help to generate a lot of revenue for the company if the customers are satisfied with their products.

\section{Conclusion}

More and more people are joining one social network or another at an increasing pace. Social media engagement is an essential part of marketing, what and how you share online will determine whether or not 
you'll get a response. We conclude that it's about time small/medium scale businesses in Ghana should take an advantage of this global phenomenon to grow their businesses. From the observations, it can be noticed that marketing on Facebook will help the companies to reach more people since Facebook has the highest number of users in Ghana. Also, since LinkedIn is known for business connections, companies in Ghana can take advantage of that and advertise their products there. YouTube also gets a lot of viewers so these companies can register for their adverts to be shown a few seconds before an actual video is streamed or during the streaming of the videos as it is done in advanced countries. The study in the long run tends to agree with Malcolm Alder, Partner of KPMG's [2] Digital Economy Practice in Australia on a statement he made which is quoted: "Organizations cannot afford not to be listening to what is being said about them, or interacting with their customers in the space where they are spending their time and, increasingly, their money too." If small and medium scale businesses cease these opportunities, there is no doubt their revenues will increase.

\section{Recommendation}

For any SMB to be successful when deploying social media, we recommend that they come up with a Social Media Marketing Strategy (SMMS). Social media marketing is way of marketing being employed by businesses to be part of a network of online community [3]. It is much easier to set up a social media account for personal use than for business purposes hence the need to plan and strategize. Before a company decides to create an account on any of the social media platforms there are questions that need to be answered. Such questions includes but not limited to the following [8]:

- Why are we doing this and what do we want to achieve?

- Who are we talking to (audience)?

- What are the best channels to use? Is it Facebook? Or Twitter? Or YouTube?

- What should the tone of our message be?

- What are the contents to be developed?

An organization must note that conversations on social medias are consumer-driven and engaging. They are not exclusive, neither are they controlled or one-sided. Below, we believe are some of the strategies an SMB can adapt when it decides to use Social Media as a marketing platform [9].

a. Audience Definition: Being able to define one's audience is the first and key step in using social media as a marketing platform to grow your business. The reason is that it helps you stay focus and also helps in the identification of the character traits and attitudes of your current and potential customers.

b. Know the resources or assets available to you: Social media, although cheap to setup is very time consuming and addictive. You should be able to allocate the number of hours or time you will be willing to devote for it. You should be able to figure out the technical know-hows, content you plan on building and how to maintain it. You should also be able to tell if you need to hire an extra to do that or you will be going to assign a member of your team to be your social media Public Relations (PR).

c. Goal Definitions: As a small business with the aim of using social media to grow your business, you must define or set your goals before you embark on this journey. The goals you set must be quantifiable, realistic and be communicated to your team. Communicating your social media goals to your team will help them not just understand but know what you plan on achieving by using this tool.

d. Content: Knowing the kind of content to use on your social media is another important factor in social marketing. As a company or a brand you should be aware that there three type of people you are likely to interact with on social media. They are a) those that already know your brand (current customers), b) those who might have heard about you but are not customers and c) those who have no idea of who you are but were intrigued about a post or an advertisement you made on a social media platform etc. Therefore having this in mind will help in the development of the content.

e. Channel: There is more than one social media channel available. You must be able to determine which channel best fits with your brand, resources, goals and target market. By thinking through this, you will be able to determine which of the social media to use. It might be Facebook or Twitter or even Pinterest. You must bear in mind that you must be willing to interact, answer questions and comments, etc. on whichever channel you decide to deploy.

f. Conversation: Now that you've been able to establish the above, join the conversation by liking, posting, uploading videos, tweeting and many others. Once you begin the conversation, know that whatever you say or post is a direct reflection on your company or business [12].

g. Evaluate: For every business it is vital to evaluate any decision we make concerning our businesses. After a few weeks or months on social media you should be familiar with the ropes of social media - the ins and outs of social media, what works, what goes well with your followers, how they prefer to be engaged etc. the evaluation will help you to track your progress in real-time, develop strategic offers and others [11]. 


\section{Extension of Research}

This research was focused on the opinions or views of the consumer. We believe that further research needs to be done where the SMBs who have embarked on the journey of using social media, as a marketing platform will be our main focused. These SMBs will also give us an insight to the kind of challenges these SMBs are facing with the use of social media and if they indeed are making a return on the investments they have made on social media.

\section{Acknowledgements}

We want to acknowledge all who took the survey to make this research possible. We wouldn't have come this far without your input.

\section{References}

[1]. A Lombard. "The Human Side of B2B Social Media: Eight Benefits of Social Media Marketing”. (2013).

[2]. KPMG International. (2011). "Going Social: How businesses are making the most of Social Media.'

[3]. R Williams. "What is Social Media Marketing?" Retrieved from www.orangejack.com on March 20, 2014

[4]. M Stelzner. "Social Media Marketing Industry Report: How Marketers Are Using Social Media to Grow Their Businesses." (2013).

[5]. J Jantsch. "Lets Talk Social Media for Small Business (Version 2)."

[6]. Community Futures PA and Districts. “An Introduction to Social Media for Small Businesses”. Blue Beetle Books. (2012).

[7]. T Merrill et al. "Social Media: The Business Benefits May be Enormous, But Can the Risks --- Reputational, Legal, Operational --Be Mitigated?" (2011)

[8]. Digital Communications. Tuft University. "Social Media Overview". Retrieved from http://webcomm.tufts.edu/social-mediaoverview13/ on March 20, 2014

[9]. D. A. Smith. "Social Networks: The Next Generation" Global Futures \& Foresights, (2010).

[10]. http://outthinkgroup.com/tips/the-6-types-of-social-media

[11]. L Simonds. "Business Growth and Social Media." June 28, 2013. Retrieved from http://business.time.com/2013/06/28/businessgrowth-and-social-media/ on March 20, 2014.

[12]. M Emerson. "7 Social Media Steps for Small Business Growth." Dec 4, $2013 . \quad$ Retrieved from http://blogs.salesforce.com/company/2013/12/social-media-smb-gp.html on March 21, 2014

[13]. G Karol. "Survey: 'Hyper Growth' Small Businesses spending more on Social Media" Published on February 19, 2014. Retrieved on http://smallbusiness.foxbusiness.com/entrepreneurs/2014/02/19/survey-hyper-growth-small-businesses-spending-more-onsocial-media/ on March 21, 2014 